\title{
Can Artificial Intelligence Have a Near-Death Experience? A Critical Look at the Ultimate Text
}

\author{
Susan C. Gunn, M.A. \\ Kent State University, Kent, $\mathrm{OH}$
}

\begin{abstract}
Since a computer model begins as an instance of writing, that is, a "text," it is appropriate to examine this kind of discourse through the perspective of literary criticism. I examine Stephen Thaler's (1995) "intelligent" computer program and conclude that the gedanken creatures are constructed upon a structuralist theory of the text, which cannot support a complete simulation of human intelligence or experience.
\end{abstract}

In 1950, Alan Turing proposed that if a computer were some day programmed to mimic human behavior to the extent that a human interrogator could not distinguish the machine from a human, then simulated and actual thinking would be the same, and the machine could be credited with genuine intelligence (Wood, 1988). But even if a machine could be programmed to imitate human linguistic behavior flawlessly, the question of whether this is sufficient reason to ascribe intelligence remains open (Ringle, 1979). It is one thing to imagine a computer that can simulate conscious thought, as Stephen Thaler has done in the hypothetical lives and deaths of his gedanken

Susan C. Gunn, M.A., is a Ph.D. candidate and Teaching Fellow in the Department of English at Kent State University in Kent, $\mathrm{OH}$. This editorial was written when she was a graduate student in the Department of English at Southwest Texas State University in San Marcos, TX. Reprint requests should be addressed to Ms. Gunn at 605 Windsor Road, Round Rock, TX 78664. 
creatures (Thaler, 1995). However, to imagine a machine possessing an unconscious is quite another matter, and raises the question of whether such a "creature" could be considered intelligent in the same way as humans (Rothfork, 1984).

As artificial intelligence (AI) evolved, researchers split into two camps. In the strong AI computationalist view, anything worth knowing can be reduced to binary logic (Bloomfield, 1987). Computationalists believe that they are developing a hard, scientific theory of intelligence and consciousness. The weak AI holists maintain the position that intelligence involves intentionality, which only a brain can possess (Waldrop, 1987), and that AI operates on a level somewhere between "mind" and "body" as these are traditionally understood (Ringle, 1979). The two camps are based on two conflicting and irreconcilable sets of beliefs, but share a belief that the brain produces consciousness (Bloomfield, 1987). Neither side entertains the possibility that the brain might receive and transmit consciousness in a way similar to the way a television set selectively picks up and transmits programming from a reality outside itself (Lund, 1985).

Are humans mere information processors and the world an aggregation of information to be processed, as the computationalists claim? Is the mind a program running on a biological computer, the brain, or is being human more complex than that? Is it possible for the program to run without the biological hardware, or without any hardware at all? Is there a mystery within ourselves, even beyond ourselves, to which we are connected?

Jean-Francois Lyotard (1991) asserted that the force driving technological development is the need to transfer our human software (mind with its capacity for language and memory) into hardware (a mechanical body somehow evolved from the biological organism) that does not depend upon conditions on earth for survival. The underlying fear could be the human race's horror of future annihilation, the individual's fear of his or her own personal death, or the overwhelming inability to keep up with the speed of social and cultural change in the late 20th century, but the question that continually arises is whether or not intelligence is separable from the biological body. The search for answers is complicated by the fact that no universally accepted criteria for defining intelligence or life exist (Gardner, 1983/1993; Thaler, 1995). 


\section{Strong AI: The Computationalist View and Structuralist Theory}

The basic tenets of the strong AI position, which is heavily indebted to scholars such as Marvin Minsky, Herbert Simon, and Allen Newell, are that (1) thinking is information processing; (2) information processing is computation, which is the manipulation of symbols; and (3) machines can and will be developed to process symbols as well or better than humans, and Turing was right that a perfect simulation of thinking is thinking (Waldrop, 1987). The strong AI position is that machine intelligence will overtake and surpass human intelligence.

Minsky proposed that mind arises from nonmind through the interaction of various internal agents and components, forming a closed system greater than the sum of its parts. It is a matter of combining the right proportions of biological substances, electronic stimuli, or both. Minsky believes that we feel certain emotions because we think; therefore, if one can think then one can also feel (Waldrop, 1987). Roger Schank, however, does not concern himself with the troublesome problem of explaining emotion. For him emotion is irrelevant: "Whether or not a computer can feel love does not affect its ability to understand" (Schank, 1979, p. 222).

Strong AI proponents' belief in the eventual superiority of machines over human brains is the hallmark of their faith in the ultimate power of technology (Bloomfield, 1987). The rational positivism of the last century has created an illusion of autonomy for technical reason: "The paradigm of science and technical reason constitutes a closed system which elaborates means and methods and flow charts but contains no ends" (Rothfork, 1984, p. 3). The binary logic of machine intelligence is the spirit, if one can call it that, of the root-tree and the foundation of strong AI, behavioral psychology, and scientific linguistics (Deleuze and Guattari, 1987).

Ferdinand Saussure's scientific concept of language is a closed and homogeneous system of signs, two-sided figures consisting of signifier and signified (Saussure, 1988). A systematic, static linguistic structure in which the relationship between the sign and its referent is one-to-one and arbitrary is compatible with strong AI. The binary relationship between sign and referent is exactly like the world between 0 and 1 inhabited by Thaler's gedanken creatures. Their universe is the embodiment of Roland Barthes' closed text, consisting of 
its own internal logic, referring only to itself, about itself (Wood, 1988).

For Barthes there is no author, only a scriptor who is merely the "instance" of writing, infusing no meaning into the text. Enunciation, as Barthes calls it, is an empty process that functions independent of any interlocutors (Barthes, 1988). It is not even the artificial internal structure of the text that matters, be it writing or computer language; it is only the appearance of intelligence that should be judged: "The dominance of signification confirms the validity of the apparent intelligence of the machine, the independent viability of the simulation, the representation" (Wood, 1988, p. 216). Wood (1988) argued that the intelligent computer in the Turing test is a self-contained, independently viable sign in itself: it is signifier in that it represents human thinking, and signified in that its artificial representation of human intelligence, is, in fact, real thinking. Thaler (1995) used this same logic to assert that his simulated gedanken deaths both represent (signify) the experience of death for humans and constitute the actual (signified) experience of death.

\section{Holism: The Symbolic, the Semiotic, and the Sublime}

The opposing holist point of view owes its articulation to Hubert Dreyfus, John Searle, and Joseph Weizenbaum. Although they believe that intelligence is an organic function of the brain, these researchers hold that thinking is not reducible to mere information processing (Waldrop, 1987). For them, psychology's mission is to explain human consciousness, cognition, and intention in terms that will ultimately unite psychology to physiology (Dennett, 1979).

Howard Gardner (1983) identified seven areas of human intelligence that develop and function more or less independently of each other, but make up an integrated whole. Five of these have been simulated, or at least attempted, in $\mathrm{AI}$ : logical/mathematical intelligence, simulated by AI subfield problem-solving; linguistic intelligence, simulated by natural language understanding; spatial perception, simulated by computer vision; bodily/kinesthetic intelligence, simulated by robotics; and musical intelligence, on which Minsky is working. For the two other areas, self-awareness and awareness of others, there is no equivalent in AI practice (Waldrop, 1987). Thaler's gedanken universe offers a metaphor for what these 
processes might look like represented in mathematical symbols. However, the gedankens' solely symbolic nature establishes their inadequacy as models of actual human experience, which, as Julia Kristeva and Lyotard claimed, is indebted to the semiotic and the sublime as well. We will come back to the semiotic, which I see as an expression of the unconscious, and the sublime, which equates to the infinite, further on.

Metacognition, or "knowing how we know," has been explored in AI knowledge engineering, but with limited success (Crevier, 1993). The ability to recognize that one thing is like another and draw inferences is the distinguishing feature of human common sense. Reason, learning, and creativity depend on the ability to perceive that facts or questions at hand resemble prior experience. Computers generally do well in simple, abstract, neat domains, but analogy is messy. Analogical reasoning seems to be a critical component missing from AI (Waldrop, 1987).

Both Searle and Weizenbaum have made significant contributions to AI research in natural language understanding, yet they do not share the enthusiasm of the strong AI proponents. Searle based his objections to AI on its lack of intentionality, which for him is synonymous with mind, soul, spirit, or awareness going far beyond formal manipulation of symbols (Waldrop, 1987). Lyotard recognized that human processing of symbols is not only arbitrary, as in semantics and syntax, but also recursive and metacognitive. Mind processes raw data and is able to observe and take into account how it went about that processing task. Lyotard (1991) believed that the human ability to perceive from the "outside" and the "inside," which he called "transcendent immanence," derives from the symbolic and recursive mastery of language. Thaler's gedankens are limited not only by their closed universe, but also by the fact that they possess no language for communication among the species (Thaler, 1995).

Gilles Deleuze and Felix Guattari took sides in the AI debate when they wrote that "everybody knows that language is a heterogeneous, variable reality" (1987, p. 100). The claim of linguistics to be "pure science of language" is in reality the mere extraction of a set of constants from the multiplicity of variables (Deleuze and Guattari, 1987). And in the creative process the mind is not directed in a series of if/then steps; it does not follow a set of rules. Rather, the mind is suspended as it waits to receive inspiration (Lyotard, 1991).

For the holists, thought is not binary and tree-like, reducible to if/then commands and flow charts. It is an infinite network, not a 
hierarchy, and is characterized by multiplicity rather than dualism. In human intelligence, as in the textual rhizome, any point can connect with any other: "The tree imposes the verb 'to be,' but the fabric of the rhizome is the conjunction, and ... and . . . and" (Deleuze and Guattari, 1987, p. 25). Scott Fahlman offered this analogy to compare and contrast human thought with computer logic:

You, the reader, want to know the name of Napoleon's mother, so you go to the Library of Congress to research the matter:

1. You go to the stacks, begin with the first book on the first shelf and search every single one till you find the tiny bit of information you need. This is conventional computer memory.

2. You go to the card catalog, check references, then search the appropriate reference. This is AI.

3. You stand in the main hall, yell out, "What is the name of Napoleon's mother?" The book with the answer hears your call, jumps up in its remote corner of the Library of Congress, and calls the answer back to you. This is human intelligence. (Waldrop, 1987, p. 62)

Fahlman's anecdotes are analogous to breaching or habit, scanning or remembering what is forgotten, and passing or working through and beyond any reminder of the forgotten to the realm of the uninscribed, the unpresentable (Lyotard, 1991). Any worthy representation of human intelligence must perform all three operations with ease. In other words, it must connect to the symbolic, the semiotic, and the sublime.

\section{Poetic Language and AI: Irreconcilable Differences}

No computer is yet able to recognize a face or derive knowledge from sources outside its own internal program, and the solutions are not in sight (Waldrop, 1987). It seems that no matter how intelligent machines become, their binary logic is unequal to the challenge of human common sense, a problem more formidably difficult that the early AI researchers conceived. Routine mental processes like imagining, intuition, and inspiration are intractable problems for AI (Waldrop, 1987). Even in the realm of neural networks, so-called "fuzzy logic," the world of $0 / 1$ is the only world from which machine intelligence can draw its inferences, as Thaler's gedanken creatures illustrate. 
Thaler described his creatures' mathematical responses to infinitesimal gradations in the binary universe as "sense" and "imagining," and demonstrated that his creatures respond in mathematically predictable ways to changes in their closed environment. But what might a gedanken do when faced with, let us say, the square root of -1 or anything else outside the boundaries $0 / 1$ ? Whether or not a gedanken creature can interact with less than 0 , greater than 1 , or a dimension of reality that completely envelops its closed, binary world, that other universe does exist.

Here I will make a rash, and maybe naive, statement of my own: that even if $\mathrm{AI}$ evolves to the point of simulating human common sense, it must remain completely and hopelessly incompetent in the area of poetic language. Plato insisted that poetry is a dangerous and destabilizing social force. With all due respect to Plato, I think that a world with no poetry, no myth, no frame of reference for the semiotic and the sublime, would be intolerable. Nothing is more inhuman and dehumanizing than the technocratic reign of terror dominating our daily life (Rothfork, 1984). It is poetry that illuminates the universe outside of $0 / 1$ and stands between the human spirit and complete automatization (Kristeva, 1988).

Scientific linguistics is involved with a direct, symbolic, and syntactical relation between signifier and signified to the exclusion of all that is nonlinguistic, even the speaking subject. In contrast, semiotics is concerned with "specifying the functioning of signifying practices such as art, poetry, and myth that are irreducible to language object" (Kristeva, 1984, p. 22). The subject is always both semiotic and symbolic. Therefore, no signifying system can be exclusively one or the other, but must be indebted to both (Kristeva, 1984). In other words, meaning is found not only in $0 / 1$, but in all that is outside and beyond it, whatever that may be. Kristeva (1984) acknowledged a presymbolic, noncognitive stage of the semiotic that precedes the establishment of the sign. All that comes before sign and syntax is necessary to language acquisition, but is not identical to language (Kristeva, 1984).

Machine language, because it is merely symbolic, is a counterfeit of human language, with no reality past its superficial linguistic meaning (Rothfork, 1984). Computers "think" in literal terms, with no relation to semiotics. Even Thaler's clever gedankens cannot process irony, metaphor, or metonymy. Techniques of literary invention like free association and fantasy are simply beyond the capacity of machine intelligence. 
To illustrate this point, let us examine AI's difficulties in constructing a narrative, defined as a simple discourse involving one speaker, one story line, and clear connections between the parts of the story (Samet and Schank, 1984). A complete theory of coherence should describe not only the end points in the narrative chain, but also the steps in the chain. It must account for the procedures that determine the steps as well (Samet and Schank, 1984).

Even if one begins with a very small set of inferences, the number of possible combinations grows very quickly. The result, combinatorial explosion, is one of the most vexing problems for AI. For example, in the sentence, "The baked salmon sounded good, and he ordered it," the computer might sort through all the possible inferences and still interpret the sentence, "The baked salmon sang well and he ordered it [to stop singing]" (Samet and Schank, 1984, p. 72). It is not likely that a human reader would make that mistake Jerry Samet and Schank admitted with apparent reluctance that "Human cognizers do avoid combinatorial explosion" (1984, p. 71). When the possible sets of inferences are limited by a script-based program, AI has been able to create characters for soap-opera plots, but as of yet no storytelling algorithms have resulted from this effort (Lebowitz, 1984). Marie Laure Ryan concluded as recently as 1991 that "The real importance of the seemingly hopeless enterprise of teaching computers the art of spinning tales does not reside in the output, but in the opportunity to test hypotheses" (p. 257, italics added). In sum, the computational method is inefficient and unmanageable in generating simple narrative, let alone the complexities of argument and conversation.

One would think that after all the difficulties encountered in narrative generation the $\mathrm{AI}$ computationalists would not attempt poetry, but programs have been written to conjugate verbs, provide "correct" antecedents for nouns and pronouns, and determine the form of its own output. In other words, the program obliterates the functions once assigned to the author, and to its proponents it appears to create coherent poetry (Ernst, 1992). The coherence of computer poetry is questionable, however, and I personally find little coherence and creative genius in it.

The problem, of course, is not computer technology itself, but its application. Users of such programs are not creators of literary works; they are computer operators. The program's concern for technocratic absolutes and its inability to process poetic ambiguity relegates computer poetry to a hopelessly structuralist literary universe. 
It reverses the liberating, opening process begun in the avant garde of the early 20 th century and confines poetry once again in a neoSaussurean prison. Further, the output embodies the ultimate alienation of producer and reader from each other, themselves, and literature. These roles converge onto each other and collapse into a void as meaningless as the simulated deaths of the gedankens (Ernst, 1992; Thaler, 1995).

Weizenbaum (1976) recognized that concepts, ideas, and images irreducible to "clearly stated ordinary language," that is, made comprehensible to computers, lose their function and power. They are as good as dead in a world that privileges dualistic, binary logic. And the burden of proof that the matter at hand has been "clearly stated" rests on the poet. Lyotard (1991) deplored the reduction of language into bits, the tiniest units of information, leaving no space outside of $0 / 1$ for the imagination to play.

The truth is that poetic language is growing, rhythmic, cyclical, and always engaged in struggle. The origin of the rhythms preceding and existing outside language is a mystery (Kristeva, 1988). Even Thaler (1995) admitted that human experience, unlike the gedankens', includes a "self concept," but his binary creations offered no explanation of where such a concept might come from. Yet, no one on either side of the AI fray is willing to concede the possibility of a hidden reality beyond the reach of current scientific analysis and understanding (Waldrop, 1987). And what science cannot explain it tends to ignore.

\section{AI Culture and Values}

Kristeva (1988) claimed that scientific linguistics privileges the artifact at the expense of the process and renders the speaking subject irrelevant. She insisted that the ethical practice of linguistics calls for a shift of emphasis from the product, or artifact, to the dialectic between product and process and the imprint of the speaking subject upon this dialectic:

The poet is put to death because he wants to turn rhythm into a dominant element; because he wants to make language perceive what it doesn't want to say, provide it with its matter independently of the sign and free it from denotation. (1988, p. 236, italics added) 
No better argument for her position exists than the closed-text lives and deaths of the gedanken creatures.

The current fetishization of technology allows the value structure and assumptions embedded in AI to go unnoticed, and therefore unquestioned. A machine's "decision" is not its own, but rather the embodiment of policies and decisions made by humans (Waldrop, 1987). Weizenbaum (1976) saw the obsession with computational calculation as evidence of the dominating influence of instrumental reason, a form of rational positivism in which means tend to become ends in themselves. He warned that the computer enslaves minds with no other resources to call upon. Thought is reduced to calculation or contemplation of the calculable. Human intelligence is "dumbeddown," transformed to mimicry of machine processes (Bloomfield, 1987). Perhaps such enslavement is one aspect of what Lyotard (1991) referred to when he suggested that humans are under constraint to become inhuman.

We may someday build analogic thinking machines with indestructible bodies, as Lyotard wrote we must, so as to flee the doomed earth and avoid annihilation when the sun explodes in 4.5 billion years; but it may take us that long to do it. Intelligent mechanical bodies evolved from our biological organisms would satisfy Lyotard's desire to preserve human intelligence from just such a disaster. Thaler asserted that "protoplasmic and machine evolution are one and the same" (1995, p. 164) and called for appreciation of the connection between biology and its mathematical simulation. In short, he asked us to believe the Turing test: the simulation is the real thing.

I will grant that AI has done a good job with computation and robotics, but it has not lived up to its early billing. Sara Hedberg (1995) defended AI, claiming that it was oversold by its proponents and generally misunderstood by the public. She cited examples of expert systems currently at work in a broad range of applications, and restated AI's mission to imbue computers with human capabilities. However, in her defense of AI, she called attention to one of its most serious weaknesses. Any given expert system operates in a narrowly defined domain, and no one has yet combined the AI equivalents of Gardner's categories of intelligence (that is, those five for which an $\mathrm{AI}$ equivalent exists) into an integrated system. No one has yet produced a computer that can write a decent soap opera all by itself, and the problem of combinatorial explosion shades the future of this endeavor. And how could a machine with no comprehen- 
sion of the semiotic or the sublime, the unconscious or the unpresentable, ever write poetry?

I have said above that both the strong AI camp and the holists share, to one degree or another, a common belief in the biological origin of mind. In other words, consciousness, thought, the soul are all products of properly organized matter, and the physical processes that occur in the brain fully explain our mental processes (Crevier, 1993). However, another point of view suggests that the seat of mind is not biological, but derives from the unconscious, the infinite. If this view is correct, then a machine, by virtue of having no unconscious, can never achieve the same quality of consciousness as human mind (Rothfork, 1984). The rhythms and mysteries that Kristeva identified as noncognitive and presymbolic are opaque to machine mind. No adroit and fortuitous combination of biological processes, no infinitesimal gradations between 0 and 1, no scientific linguistics, no closed-text theory will ever approach what Kristeva held as the center of the issue.

The locus of mind carries profound implications for literary theory. If one can accept the brain as the origin of mind, then one can believe in Minsky's closed system of producing mind out of nonmind by biological or electronic means, aligning oneself with structuralism, behavioral psychology, and strong AI. If mind is reduced to mere biological function, then there is no way of accounting for anything beyond the calculable, the concrete, that which can be replicated. That seems to exclude anything resembling the unconscious or the infinite. On the other hand, if one grants mind to the unconscious and the infinite, then one stands on the side of the rhizome, the semiotic, the unpresentable. And the weak AI proponents, the holist camp, need to get off the fence, for, unless they can bring themselves to acknowledge the role of the unconscious and the infinite, their position is indefensible.

\section{Separability: The Mind/Body Problem}

The most cogent argument for the biological origin of mind is the anatomical evidence. It is a fact that damage to specific areas of the brain produces specific kinds of disorder (Crevier, 1993). Impaired intelligence from brain damage, however, can be compared to a concert pianist sitting down to play a Rachmaninoff concerto on a piano that has been dropped from a third-story window. The music will 
certainly be less than concert quality, but the problem is the broken instrument, not the musician struggling to play it. The brain-injured person lacks not intelligence, but rather the ability to express or perceive it because of his or her impaired instrument. Its function is reduced, but the nature of mind itself is the same at its infinite source.

If the biological brain is the producer of mind then, when an individual brain dies, its intelligence dies as well. However, if the brain is an instrument or a transmitter, then there is no more reason to believe that intelligence dies with the brain than that turning off the radio annihilates the sound waves permeating the air (Lund, 1985). Thaler (1995) claimed to have shown, by the behavior of his gedankens as he killed them off, that transcendent experiences reported by near-death survivors are hallucinations produced from environmental features as the brain dies. He compared the phenomenon to a demon rushing hysterically around inside a closed piano, randomly cutting piano wire, producing recognizable melodies as it destroys the instrument. I do not agree that a skilled musician's intelligent and sensitive interpretation of Rachmaninoff (or even "Chopsticks") is comparable to the random noises of a crazed demon cutting piano wire. Nor am I prepared to believe that deathbed experiences, particularly those that include knowledge of events taking place far from the death scene while a resuscitated subject is clinically dead, are comparable to noise generated as the biological brain shuts down. An alternative view of the brain as a selective transmitter of intelligence, or perhaps a reducing valve, restricting conscious awareness to what is practically useful, seems more believable in the light of current near-death research's lessons about consciousness (Lund, 1985).

Some scientists point to the acceleration of the gradual displacement of man from the center of the universe as a result of AI's potential to create, out of inert matter, machines with thought, awareness, feelings, and emotions (Crevier, 1993). Just as Nicholaus Copernicus, Charles Darwin, and Sigmund Freud shattered human narcissism with their discoveries, so some believe that AI will prove that man does not have the monopoly on mind (Lyotard, 1991). One could just as easily defend the view that humanity, stripped of our former arrogance and ignorance because of these discoveries, is now in a position humbly to admit that we do not know all there is to know, that we do not understand much of what we know, and to recognize the invisible, the infinite, the unseen that gives us our sight (Lyotard, 1991). 
Lyotard (1991) wrote of the sublime that it cannot be represented itself; all that can be represented of it is that it is. Where rhetoric and poetics are didactic forms, the sublime embraces emotion and indeterminacy. All language, including mathematics, fails before the sublime, and where beauty gives a sense of calm, the sublime gives rise to instability, agitation, a pleasure akin to pain, a terror followed by suspense of terror, leading to delight. The artist and the poet and perhaps even the scientist are freed from the Aristotelian need to imitate nature, and drawn instead to representing that the unpresentable simply is (Lyotard, 1991). It equates to the infinite.

But what has this to do with the separability of intelligence from the body? Lyotard (1991) argued that the perishable human body is a hindrance to the survival of intelligence, but it is the only available analog for the complex processes of human thought. He recognized the failure of the closed-text notion of mind. He could not quite imagine an artificial body that could perceive and manifest all that mind is, but he assumed that the survival of mind depends on science's ultimate ability to manufacture or evolve a body that not only imitates but replicates the natural one. Engineer Hans Moravec believed that one day robot surgeons will replicate human brain components just like any other modular components, custom built for each individual, and replace the biological brain, module by module, with an artificial neural net. All this would happen under local anesthesia with no interruption in awareness (Crevier, 1993). And Lyotard, glancing up from his watch as he counts down the death of the sun, might smile just a little.

But if we believe that mind derives from the unconscious and the brain is merely the instrument of mind, not its source, then we do not need technology to replicate the body in order for mind to survive. The biological brain may be merely the point of contact between two realities (Lund, 1985). Current near-death research provides mounting evidence that survival after bodily death, with memory and personality intact, is a reality (Crevier, 1993). Many near-death survivors report seeing their abandoned biological body from a distance, while occupying a different sort of body during the experience (Crevier, 1993). It seems that mind, or its host, consists of a loosely constructed type of matter intimately related to, but separable from, the densely constructed organism of the visible body. Lyotard (1991) asserted in apparent agreement that matter is energy, mind is contained in vibration, and apparent differences between matter and nonmatter are merely variations in density and vibrational frequency. 
Moravec's imaginary artificial brain transplant suggests the possibility of transferring intelligence from natural to artificial housing in the distant future. Current near-death research suggests that transfers of intelligence are commonplace in nature, although the receiving host is a form of matter unknown to us and involves a mechanism we do not yet understand (Crevier, 1993).

\section{Conclusion}

What are we to make of all this? Kristeva would argue that the mounting evidence for the unconscious and infinite locus of mind makes her proposed ethical practice of linguistics all the more urgent. Our concern over a future in which we are surrounded by intelligent mechanical bullies is somewhat misplaced. It is more frightening to see the many and subtle ways that we humans are becoming more like computers in our ways of thinking and speaking (Bloomfield, 1987). We have acquiesced to the tree structure, the closed text, the symbolic, and confined ourselves to the universe of Thaler's gedanken creatures, the world between 0 and 1 . In so doing, we are severing our connection to the semiotic and the sublime, which equate to the unconscious and the infinite. Lyotard asked the question, "What else remains as politics except resistance to this inhuman?" (1991, p. 7). His question begs an answer: we must resist! And if, as Kristeva insisted, poetry is all that stands between us and complete automatization, we had better be about the business of making poetry, illuminating the semiotic, giving representation to the truth that the unpresentable is!

\section{References}

Barthes, R. (1988). The death of the author. In D. Lodge (Ed.), Modern criticism and theory (pp. 166-171). New York, NY: Longman.

Bloomfield, B. P. (1987). The culture of artificial intelligence. In B. P. Bloomfield (Ed.), The question of artificial intelligence (pp. 59-105). London, England: Croom Helm.

Crevier, D. (1993). AI: The tumultuous history of the search for artificial intelligence. New York, NY: Basic Books.

Deleuze, G., and Guattari, F. (1987). A thousand plateaus. Minneapolis, MN: University of Minnesota Press.

Dennett, D. C. (1979). Artificial intelligence as philosophy and psychology. In M. Ringle (Ed.), Philosophical perspectives in artificial intelligence (pp. 57-80). Brighton, England: Harvester. 
Ernst, J. (1992). Computer poetry: An act of disinterested communication. New Literary History, 23, 451-465.

Gardner, H. (1993). Frames of mind: The theory of multiple intelligences (10th anniversary ed.). New York, NY: Basic Books (Original work published 1983).

Hedberg, S. (1995). Where's AI hiding? AI Expert, 10(4), 17-20.

Kristeva, K. (1984). The semiotic and the symbolic. In Revolution in poetic language (pp. 21-30). New York, NY: Columbia University Press.

Kristeva, J. (1988). The ethics of linguistics. In D. Lodge (Ed.), Modern criticism and theory (pp. 223-239). New York, NY: Longman.

Lebowitz, M. (1984). Creating characters in a story-telling universe. Poetics, 3, 171 194.

Lund, D. H. (1985). Death and consciousness. New York, NY: Ballantine.

Lyotard, J.-F. (1991). The inhuman: Reflections on time (G. Bennington and R. Bowlby, Trans.). Stanford, CA: Stanford University Press.

Newell, K. B. (1983). Pattern, concrete and computer poetry: The poem as object in itself. Bucknell Review, 27, 159-173.

Ringle, M. (1979). Philosophy and artificial intelligence. In M. Ringle (Ed.), Philosophical perspectives in artificial intelligence (pp. 1-22). Brighton, England: Harvester.

Rothfork, J. (1984). The ghost in the machine: Stanislaw Lem's mortal engines. Liberal and Fine Arts Review 4(1), 1-18.

Ryan, M.-L. (1991). Possible worlds, artificial intelligence, and narrative theory. Bloomington, IN: Indiana University Press.

Samet, J., and Schank, R. (1984). Coherence and connectivity. Linguistics and Philosophy, 7(1), 57-82.

Saussure, F. (1988). The object of study. In D. Lodge (Ed.), Modern criticism and theory (pp. 1-14). New York, NY: Longman.

Schank, R. C. (1979). Natural language, philosophy, and artificial intelligence. In M. Ringle (Ed.), Philosophical perspectives in artificial intelligence (pp. 196-224). Brighton, England: Harvester.

Thaler, S. L. (1995). Death of a gedanken creature. Journal of Near-Death Studies, 13, 149-166.

Waldrop, M. M. (1987). Man-made minds. New York, NY: Walker.

Weizenbaum, J. (1976). Computer power and human reason: From judgment to calculation. San Francisco, CA: Freeman.

Wood, M. McG. (1988). Signification and simulation: Barthes' response to Turing. Paragraph, 11, 210-226. 